REVISTA ANDALUZA DE ANTROPOLOGÍA.

NÚMERO 10: ANTROPOLOGÍA Y EPISTEMOLOGÍAS DEL SUR: EL RETO DE LA DESCOLONIZACIÓN DE LA PRODUCCIÓN DEL CONOCIMIENTO

MARZO DE 2016

ISSN 2174-6796

[pp. 119-142]

http://dx.doi.org/10.12795/RAA.2016.10.07

Recibido: 31/12/2015

Aceptado: 28/01/2016

\title{
DESARROLLO Y COLONIALIDAD: UNA EPISTEMOLOGÍA PARA EL ANÁLISIS CRÍTICO DEL DESARROLLISMO ${ }^{1}$
}

\section{DEVELOPMENT AND COLONIALITY: AN EPISTEMOLOGY FOR CRITICAL ANALYSIS OF DEVELOPMENTALISM ${ }^{1}$}

Víctor Bretón

Universitat de Lleida

Pablo Palenzuela

Universidad de Sevilla

\section{Resumen.}

De 1990 en adelante, los discursos y las prácticas del desarrollo han recibido, desde las llamadas posturas posestructuralistas, críticas mordaces y profundas. Esas críticas han ido abarcando todo lo relacionado con el ámbito discursivo del desarrollo, poniendo de manifiesto de qué manera éste se traducía en una serie de prácticas de los actores sociales que, de manera directa, incidían sobre la realidad, reafirmando y consolidando la geopolítica del pensamiento establecida por el propio discurso del desarrollo. Uno de los elementos más remarcables de esos planteamientos fue la denuncia de la colonialidad del conocimiento científico, aliado estratégico durante décadas del complejo desarrollista.

1. Una versión preliminar de este artículo fue presentada como comunicación al simposio "Antropología y Descolonialidad" del XIII Congreso de Antropología en Tarragona, septiembre de 2014 
En este artículo se pretende mostrar cómo ese énfasis en los aspectos discursivos fue lastimosamente alejando la metodología de los investigadores del análisis etnográfico de los actores sociales, contribuyendo implícitamente a la construcción de unas imágenes estereotipadas de éstos muy alejada de lo que una mirada desde abajo y desde adentro parece sugerir. A partir del análisis crítico de la ejecución de algunas iniciativas emblemáticas en materia de desarrollo en los Andes ecuatorianos y de la contrastación de discursos (como el del Buen Vivir) que en teoría están amparando la intervención sobre el mundo indígena de los conocidos como gobiernos progresistas en la región, el texto contrapone esas imágenes esencializadas del universo indígeno-campesino con la que brinda una perspectiva etnográfica anclada en la economía política.

\title{
Palabras clave.
}

Desarrollo, posdesarrollo, colonialidad, epistemología, Andes, Ecuador

\begin{abstract}
.
Since the 1990s, the discourses and practices of development viewed from standpoint of poststructuralist perspectives have been the subject of a profound and mordant critique. Poststructuralist critique has focused on how the discourses of development are tangibly translated into social practices by social agents that directly influence reality making while reaffirming and consolidating the geopolitics established by the very discourse of development itself. One of the most remarkable achievements of this critical stance was the denunciation of the colonial bias of scientific knowledge that had been for decades a strategic component of the discourse of the development paradigm. In this article we argue that the emphasis on the critical deconstruction of the discursive aspects of anthropological research has regrettably distanced researchers from an ethnographic analysis of social actors and has therefore contributed to a stereotyped image of these actors that is very far removed from a grassroots and internal perspective. Focusing on a critical analysis of emblematic initiatives of development in the Ecuadorian Andes and on the discourses such as the Buen Vivir that theoretically are sustaining the intervention on the Indigenous worlds by the albeit progressive governments in the region, our article contrasts these essentialzed images of the indigenous-peasant universe with an ethnographic perspective anchored in the politic economy of the region.
\end{abstract}

\section{Key Words.}

Development, postdevelopment theory, coloniality, epistemology, Andes, Ecuador 


\section{INTRODUCCIÓN}

La revisión critica de los discursos y las prácticas del desarrollo, en su modelo hegemónico, ha cumplido ya varias décadas desde el momento en que se constató, tanto desde el norte como, sobre todo, desde el sur, la ineficiencia de esta estrategia de espectro transnacional para disolver de las estructuras causantes de la dialéctica desarrollo/subdesarrollo y sus efectos perversos de naturaleza identitaria, ecológica y patriarcalista, entre otros.

De 1990 en adelante, esos discursos y prácticas del desarrollo han recibido, desde el elenco de los autores que conforman las llamadas posturas posestructuralistas, algunas de las críticas más mordaces y profundas. A diferencia del tiempo de las teorías de la dependencia, en el que la reflexión cuestionaba sobre todo los aspectos económicos y estructurales del desarrollismo hegemónico ${ }^{2}$, con los posestructuralistas la crítica ha ido abarcando todo lo relacionado con el ámbito discursivo del desarrollo, poniendo de manifiesto cómo éste se traducía en una serie de prácticas inducidas que, de manera directa, incidían sobre la realidad, reafirmando y consolidando así la geopolítica establecida por el propio discurso del desarrollo. Uno de los elementos más remarcables de esos planteamientos fue, precisamente, la denuncia de la colonialidad del conocimiento científico ${ }^{3}$, aliado estratégico durante décadas del complejo desarrollista.

Partiendo de una visión crítica de los postulados epistémicos sobre los que descansa la práctica del desarrollo (primera parte), en este artículo se pretende mostrar de qué manera ese énfasis posestructuralista en los aspectos discursivos fue alejando la metodología de los investigadores del análisis etnográfico de las realidades concretas y substantivas, contribuyendo implícitamente a la construcción de unas imágenes estereotipadas de los actores sociales muy alejada de lo que una mirada desde abajo y desde adentro parece sugerir (segunda parte).

A partir del análisis crítico de la ejecución de algunas iniciativas emblemáticas en materia de proyectos de desarrollo en los Andes ecuatorianos y de la contrastación de discursos, presuntamente alternativos -como el del Buen Vivir o el del desarrollo con identidadque en teoría están hoy día amparando la intervención sobre el mundo indígena de los conocidos como gobiernos progresistas en la región y de las instituciones del complejo desarrollista (tercera y cuarta parte), nos proponemos contraponer esas imágenes esencializadas del universo indígeno-campesino con la que brinda una aproximación

2. Ver Wallerstein (2004 [1972]), Gunder Frank (2005 [1966]), Furtado (1986 [1974]) o Cardoso (1972), entre otros

3. Aníbal Quijano (2000), autor pionero desde 1992 del análisis de la modernidad como patrón de dominación/explotación/conflicto, constata que la colonialidad del saber es parte de la matriz colonial del poder, un patrón de dominación eurocéntrico que, articulado al capitalismo, se configura como el instrumento universal de clasificación social básica de toda la población del planeta 
a esos sectores sociales desde una perspectiva etnográfica anclada en la Historia y en la Economía Política ${ }^{4}$.

\section{DISCURSO DEL DESARROLLO Y COLONIALIDAD DEL CONOCIMIENTO}

Es una idea reiterada por todos los analistas que, si hubiera que fijar una fecha icono para marcar el inicio, sin reservas, de la "era del desarrollo contemporáneo", esa sería el 20 de enero de 1949. Fue ese día cuando, en su Discurso sobre el estado de la Unión, el entonces presidente estadounidense Harry Truman hizo alusión, además de a tres puntos clave de su política exterior -apoyo a Naciones Unidas, continuidad de la reconstrucción europea vía Plan Marshall e intención de crear una organización militar común de defensa (OTAN) para neutralizar la amenaza soviética - al imperativo que los Estados Unidos tenían de ayudar a salir de la pobreza a las "regiones insuficientemente desarrolladas". Es el conocido como Punto IV, y con él dio comienzo un tiempo nuevo en el que el desarrollo, verdadero discurso civilizatorio de la segunda mitad del siglo XX, devino en una utopía de una fuerza arrolladora, legitimadora de la creación de un vasto elenco de instituciones orientadas a materializarlo y objeto de estudio de nuevas disciplinas -la Economía del Desarrollo entre ellas- centradas en develar las leyes y los modelos que habrían de permitir planificar el tránsito de los subdesarrollados al Primer Mundo ${ }^{5}$.

La entronización a escala planetaria de ese discurso y de sus correspondientes prácticas ha tenido unas consecuencias trascendentales sobre la dinámica de las relaciones entre pueblos, países y regiones. Ha convertido, en primer lugar, a la solidaridad en un imperativo moral (los desarrollados tienen la obligación ética y moral de ayudar

4. Compartimos esta triple perspectiva disciplinar para la producción de conocimiento sobre el desarrollo con nuestro colega Pierre Beaucage cuando propone: "Para entender este mundo y lograr alguna incidencia en él, hace falta combinar las herramientas de la Antropología, de la Economía Política y de la Historia. La economía política permite analizar las fuerzas y corrientes que le dan rumbo al proceso actual de reorganización del mundo en torno a un único polo de poder y ayuda a evaluar en esta perspectiva las posibilidades de éxito de los varios movimientos de oposición: campesina, sindical, indígena, de jóvenes, de mujeres. La historia ayuda a situar estas fuerzas en las tendencias de media y larga duración. La antropología puede descifrar el componente simbólico-cultural de la estrategia mundial del capital en la que reside mucho de su eficacia. Y también apreciar en qué forma los varios movimientos de oposición logran oponerle contrapropuestas políticas y simbólicas susceptibles de ser, y de aparecer, como verdaderas alternativas" (Beaucage, 2005: 78).

5. Como se ve, asumimos en este texto la acepción del desarrollo como un discurso y una praxis asociada a él, siguiendo los planteamientos de autores (posestructuralistas por más señas) como Ferguson (1990), Escobar (1998, 1999) o Rist (2002). Nos hallamos, en cierto sentido, ante una creencia quasi religiosa (Rist dixit), ante "un modelo de construcción conceptual sacralizada" (Palenzuela, 2009: 129): el dogma de que todos pueden llegar a ser como los presuntos desarrollados; una creencia traducida en un conjunto de prácticas -a menudo contrapuestas las unas con las otras- orientadas a alcanzar tan quimérica meta (quimérica por insostenible e inasumible). 
a los subdesarrollados a desarrollarse), justificando la intromisión, hasta el punto de naturalizarla en nombre del fomento del desarrollo, de unos países hegemónicos en los procesos sociales y económicos de otros periféricos. Ha generado un gigantesco mercado de la solidaridad -o de la compasión, como en su día planteara David Sogge (1998 y 2004) - cuyos clientes (los beneficiarios) son los subdesarrollados, tradicionales, atrasados o emergentes del Sur que deben (y quieren y anhelan) desarrollarse y modernizarse. Ha conseguido colonizar, pues, los imaginarios colectivos de su objeto de intervención (las poblaciones desarrollables). Ha permitido articular, finalmente, un complejo entramado institucional (el aparato del desarrollo) que genera modelos teóricos y líneas de intervención, canalizando, financiando y evaluando el proceso dialéctico de acciónreacción-cambio por él mismo estimulado.

Sesenta años después, sin embargo, a pesar de todo el elenco de agencias implicadas (desde los grandes organismos multilaterales hasta los millares de ONG comprometidas con la cooperación internacional) y de los cuantiosos recursos invertidos, los objetivos fundacionales de esta estrategia parecen inalcanzables: baste con comprobar el desfase existente entre el primero de los publicitados Objetivos de Desarrollo del Milenio reducir a la mitad la incidencia de la subnutrición en el horizonte de 2015- y las cifras reconocidas por la $\mathrm{FAO}^{6}$ en sus últimos informes anuales sobre la prevalencia de la inseguridad alimentaria en el mundo (2013) ${ }^{7}$. En cualquier caso, si tras décadas de intervenciones millonarias en pos del desarrollo la situación es la que dejan entrever las estadísticas de las mismas instituciones implicadas en su consecución ${ }^{8}$, es deducible que algo falla en los diagnósticos y en las medidas implementadas.

Tal vez una de las raíces del problema sea su misma conceptualización, puesto que se ha solido identificar el subdesarrollo como una suerte de estado patológico en la senda natural que ha de conducir a las naciones por las etapas del crecimiento recorridas exitosamente por los países ya desarrollados (Rostow, 1961). Lo más innovador del discurso del desarrollo, con todo, fue el argumentar que el rasgo esencial del Tercer Mundo era su pobreza, prescindiendo de la etiología de ésta, y que la solución radicaba en el crecimiento

6. Acrónimo en inglés de la Organización de las NacionesUnidas para la Agricultura y la Alimentación.

7. Sin menoscabo del lenguaje triunfalista que utiliza la FAO al constatar los "avances" conquistados a escala planetaria en 2013, con un total de 842 millones de personas -alrededor de una de cada ocho en el mundo- aquejadas de hambre crónica, en relación a los 868 millones contabilizados en 2010-2012 (FAO 2013). Cabe subrayar, por otra parte, la manera edulcorada en que la FAO procede metodológicamente a contabilizar los límites de lo que considera "subnutrición" (Bretón 2009b).

8. Entre otras fuentes estadísticas, el Informe sobre Desarrollo Humano que publica anualmente el Programa de Naciones Unidas para el Desarrollo (PNUD). 
económico convencionalmente entendido, convirtiendo así al mismo desarrollo en una verdad evidente, universal y necesaria. Como apostilla Rist, "definiendo el subdesarrollo como un simple estado de carencia, el economicismo imponía su orden" (Rist, 2002: 95). Este fue el fundamento epistemológico, de hecho, de una instrumentalización del conocimiento científico - por parte de la Economía del Desarrollo, desde luego, pero también de disciplinas vinculadas con el aparato desarrollista, como la Antropología Aplicada o la Sociología Rural, entre otras- al servicio de la construcción de una "verdad" -una manera presuntamente universal y unívoca de ver el mundo- que ha devenido en una suerte de sentido común articulador de un discurso de corte hegemónico a escala planetaria. Eso es lo que, desde el conocido como enfoque posestructuralismo, ha sido definido como la colonialidad del poder y del saber (Quijano, 2000; Mignolo, 2000; Lander, 2005). Un patrón de dominación que consigue, mediante la colonialidad de las subjetividades, que el modelo hegemónico de desarrollo sea aceptado como condición sine qua non de la modernización.

\section{MIRADAS ALTERNATIVAS SOBRE LOS DISCURSOS Y LAS PRÁCTICAS DEL DESARROLLO}

Los reiterados y rotundos fracasos del desarrollo y los límites de los intentos por encontrar vías o modelos de desarrollo alternativo, condujeron a algunos investigadores y analistas (como los ya citados Escobar, Rist y Ferguson), a proponer una lectura en clave foucaultiana de tal constructo histórico que apuntara a una salida posdesarrollista de ese atolladero conceptual y práctico. No debe tratarse ya -nos dirán- de ensayar más formas fallidas (por imposibles) de desarrollos alternativos, sino de buscar verdaderas alternativas al desarrollo como principios organizadores de nuestra visión, posicionamiento e intervención sobre la realidad. Las palabras no son asépticas y por ello, nos recuerda Gustavo Esteva, hay que ser cautos con el lenguaje que utilizamos:

"El desarrollo no se puede desvincular de las palabras con que se formó - crecimiento, evolución, maduración-. De manera similar, aquellos que hoy utilizan el vocablo no pueden librarse de una maraña de significados que confieren una ceguera específica a su lenguaje, su pensamiento y su acción. No importa el contexto en que se emplee ni la connotación específica que le quiere dar la persona que lo usa, la expresión resulta calificada y coloreada con significados tal vez no deseados. La palabra siempre implica un cambio favorable, un paso de lo simple a lo complejo, de lo inferior a lo superior, de lo peor a lo mejor. La palabra indica que uno lo está haciendo bien porque está avanzando hacia una meta deseada en el sentido de una ley universal necesaria, ineluctable. (...) Pero, para dos tercios de la población terrestre, este significado positivo de la palabra 'desarrollo' -profundamente arraigado tras dos centurias de construcción social- es un recordatorio de lo que no 
son. Es un recordatorio de una condición indeseable e indigna. Para escapar de ella, necesitan que las experiencias y sueños de otros los esclavicen" (Esteva, 2000: 75).

Las propuestas enmarcadas dentro de los espaciosos y difusos límites del posestructuralismo atañen a una gran variedad de aspectos y temáticas, yendo desde la apuesta por cambios en los valores y en las formas de mirar y aprehender la realidad, hasta la militancia con prácticas del día a día abiertamente anti-capitalistas, anticonsumistas o alternativas al modus operandi del homo aeconomicus supuestamente universal publicitado por la teoría económica dominante9. Trascender el desarrollo solo será factible a través de un rearme de la sociedad civil capaz de "poner controles políticos a la esfera económica" (Esteva, 2000: 97). Una tarea clave en este sentido sería la denuncia del capitalocentrismo implícito en los discursos recientes sobre la globalización. En ellos, en efecto, el capitalismo asoma como una verdad inmutable, imbatible e inevitable, dotada de un dominio y una hegemonía tal que ha llegado a imposibilitar repensar la realidad social de otro modo, por no hablar de lo quimérico que incluso hoy día parece para muchos hablar de su supresión. Hasta tal punto es así que las demás realidades -las economías de subsistencia, las formas de resistencia del Tercer Mundo, las iniciativas cooperativas, no por menores desdeñables- son vistas como subordinadas o complementarias al capitalismo, pero nunca como fuentes de diferencias económicas con significación propia.

De ahí la necesidad de descolonizar los imaginarios a fin de concebir una realidad alternativa y, para ello, la indispensabilidad de focalizar la mirada y la acción en los márgenes del sistema, en las prácticas locales, en las culturas substantivas realmente existentes e invisibilizadas por el meta-discurso desarrollista. Semejante actitud lleva a estos autores a abogar por una suerte de diálogo de saberes (Leff, 2006); un cuestionamiento en toda regla de la ciencia, de la colonialidad del conocimiento científico y, en general, de toda la episteme occidental. En este sentido, si el discurso del desarrollo es una práctica con condiciones, reglas y transformaciones históricas y no una mera "expresión

9. Realmente es difícil definir al posestructuralismo como una "escuela" en el sentido paradigmático convencional. El mínimo denominador común de los autores calificados como posestructuralistas "no fue tanto el proponer otra versión del desarrollo", como en el caso de las teorías dependentistas precedentes, "sino el cuestionar precisamente los modos en que Asia, África y Latinoamérica llegaron a ser definidas como subdesarrolladas y, por consiguiente, necesitadas de desarrollo" (Escobar, 2005: 18). Ahí cabe una extraordinaria pluralidad de enfoques y perspectivas ancladas tanto en su rechazo a las teorías clásicas de la modernización como en su alejamiento -más o menos radical, según el caso- de los planteamientos de matriz marxista. Entre ellos, el énfasis en la deconstrucción del desarrollo (Escobar, 1998); la denuncia de la colonialidad del saber y del poder a él asociado (Quijano, 2000; Mignolo, 2010); la apuesta por el decrecimiento convivencial (Latouche, 2008); o la atención al papel de las culturas, los conocimientos y los imaginarios locales en la construcción de un futuro ajeno a la noción de desarrollo (Escobar, 2005b y 2010b). 
del pensamiento", ergo cambiemos el discurso para cambiar la praxis (Escobar, 1998: 405). En cualquier caso, lo cierto es que este tipo de análisis ha abierto nuevos espacios sobre los que construir aproximaciones más eclécticas e imaginativas que antaño, dando pábulo, también, a una visión en muchos sentidos esencializada del sentido y el potencial cultural de los sectores subalternos, como veremos.

\section{4. ¿ERA DE CAMBIOS O CAMBIO DE ERA?}

Hace pocos años, Arturo Escobar (2010) se interpeló sobre la naturaleza de algunos de los procesos sociales y políticos que están teniendo lugar en Ecuador y Bolivia desde mediada la primera década del siglo XXI. Pudiera parecer, de hecho, que en esa región del mundo se estaban materializando experiencias contra-hegemónicas a nivel estatal ${ }^{10}$. Prestando atención a la dirección de la acción de gobierno de los regímenes de Rafael Correa y de Evo Morales (en ambos casos con la elaboración, aprobación parlamentaria y sanción popular de sendas constituciones -2008 en Ecuador y 2009 en Bolivia- en cierto sentido refundadoras del Estado), Escobar se preguntaba si "constituyen tales transformaciones formas alternativas de modernización, $\mathrm{o}$ [si] puede decirse que tienden a transformaciones sociales más radicales", esto es, "hacia opciones poscapitalistas, posliberales y posestatalistas, que podrían definirse como alternativas a la modernidad". Particularmente, el argumentario esgrimido giraba alrededor de la sustentabilidad -o no- de estos cambios; sobre hasta qué punto los estados "pueden mantener sus políticas redistributivas y anti-neoliberales a la vez que se abren más decididamente a las exigencias autónomas de los movimientos sociales" (Escobar, 2010: 17).

Tomemos el ejemplo de las oportunidades que parecía abrir la inclusión en esas constituciones de los preceptos del Buen Vivir, provenientes en principio de las categorías indígenas Sumak Kawsay (en quichua) y Suma Qamaña (en aymara) ${ }^{11}$. En opinión de Alberto Acosta, expresidente de la Asamblea Constituyente del Ecuador,

10. Así lo constata también Aníbal Quijano: “América Latina fue el espacio original y el momento inicial de formación del capitalismo colonial/moderno. Hoy es, por fin, el centro mismo de la resistencia mundial y de la producción de alternativas contra ese patrón de poder" (Quijano, 2007: 4).

11. La Constitución ecuatoriana de 2008 reconoce "el derecho de la población a vivir en un ambiente sano y ecológicamente equilibrado, que garantice la sostenibilidad y el Buen Vivir, Sumak Kawsay" (Artículo 14). Por su parte, la Constitución boliviana de 2009 dice que "el Estado asume y promueve como principios ético-morales de la sociedad plural: ama qhilla, ama llulla, ama suwa (no seas flojo, no seas mentiroso ni seas ladrón), suma qamaña (vivir bien), ñandereko (vida armoniosa), tekokavi (vida buena), ivimaraei (tierra sin mal) y qhapajñan (camino o vida noble)" (Artículo 8.i). 
"El Buen Vivir como principio estructurador de la nueva Constitución implica el reconocimiento de las concepciones de sustentabilidad y respeto a la naturaleza promovidos por las sociedades indígenas. Más que una declaración constitucional es una oportunidad para construir colectivamente un nuevo régimen de desarrollo basado en una economía solidaria. Esto significa alejarse de una economía sobredeterminada por las relaciones mercantiles, impulsando una relación dinámica y constructiva entre mercado, Estado y sociedad. El Buen Vivir es utopía de un proyecto de vida en común a ser ejecutada por la acción de la ciudadanía" (Acosta, 2008: 33).

Este no es un asunto menor, desde luego, pues implicaba el reconocimiento por parte del Estado de una serie de obligaciones y derechos -nos recuerda José María Tortosaprocedentes "del vocabulario de pueblos otrora totalmente marginados, excluidos de la respetabilidad y cuya lengua era considerada inferior, inculta, incapaz de pensamiento abstracto, primitiva" (Tortosa, 2009b: 3) ${ }^{12}$. Tal reconocimiento, además, se enmarca en un proyecto mucho más amplio de reconstitución de los poderes públicos, de renacionalización (al menos en parte) de las políticas económicas y de replanteamiento del equilibrio de fuerzas sociales al ínterin de cada país. Es precisamente en ese escenario complejo en el que Escobar indagaba sobre los límites del Estado en la implementación de políticas radicales -radicales en el sentido de trascender al propio Estado y de poner las bases de formas de funcionar posdesarrollistas y posestatalistas- $y$ sobre el peso que las propias inercias históricas imponen a los nuevos gobiernos de izquierda, por muy progresistas y solidarios que estos sean.

Las contradicciones constatables entre las declaraciones de principios constitucionales del tipo Buen Vivir y la praxis neo-desarrollista y neo-estatalista de las políticas públicas impulsadas tanto en Ecuador como en Bolivia, empero, ya están siendo subrayadas por diferentes analistas (Tortosa, 2009; Gascón, 2010; Viola, 2011; Martínez Novo, 2013), poniendo de manifiesto la presencia del espíritu desarrollista en la gestión del día a día

12. En esta línea argumental, para Eduardo Gudynas (2009) los derechos de la naturaleza la manida Pachamama-, sancionados en la Constitución ecuatoriana (Capítuloséptimo, Arts. 71-74), representaban un giro biocéntrico en consonancia con las cosmovisiones de los grupos étnicos y los principios de la ecología contemporánea. De manera similar, Catherine Walsh (2009) argumentaba que el Buen Vivir, presente en las filosofías y las prácticas de los pueblos indígenas y afrodescendientes durante siglos, parecía recuperarse en la refundación de los estados boliviano y ecuatoriano. 
y en la planificación de las políticas públicas en ambos países ${ }^{13}$. Con todo, el cambio de tendencia es perceptible, según Escobar, en el hecho de que los movimientos sociales que sustentan a esos gobiernos (o que les han apoyado) sí mantienen una agenda post en muchos sentidos. En esta línea argumental, se esfuerza por ver en las propuestas y en los diagnósticos que intelectuales afines y/o pertenecientes a esas plataformas organizativas vierten en el sentido de que, en efecto, el posdesarrollo y todo un hato de propuestas firmes de alternativas a la modernidad están ahí, quizás anunciando un verdadero cambio de era. Es importante remarcar aquí el papel de autores filo-indianistas como Javier Medina (2010) o Atawallpa Oviedo (2012) que, desde Bolivia y Ecuador respectivamente, han desplegado todo un esfuerzo por construir una imagen arquetípica, descontextualizada y mística de una suerte de "civilización andina" portadora de unas ontologías vitalistas y relacionales que, de manera misteriosa -en cualquier caso nunca explicada por los autores- han permanecido incontaminadas por la cultura occidental, como preservadas en frascos de formol. Es en esos espacios de resistencia donde se encontraría la verdadera esencia del Sumak Kawsay / Suma Qamaña, bastardeada y devaluada a su juicio por los discursos y prácticas oficialistas que, por igual en el Ecuador de Correa y en la Bolivia de Morales, tratan de encauzar las demandas de los pueblos originarios en andariveles neodesarrollistas ${ }^{14}$. De ahí el reto y el desafío (las "amenazas" al "genuino" Sumak Kawsay), pues al plantear "una cosmovisión diferente a la occidental al surgir de raíces comunitarias no capitalistas", rompe por igual "con las lógicas antropocéntricas del capitalismo en tanto civilización dominante y también de los diversos socialismos realmente existentes hasta ahora" (Acosta, 2011: 51). Sirvan como ejemplo algunas afirmaciones bien contundentes de este argumentario, irónicamente calificado como pachamamista desde visiones antiesencialistas (Stefanoni, 2010; Sánchez-Parga, 2011):

13. La cuestión de la deriva extractivista de las políticas económicas de Ecuador y Bolivia ha sido analizada en diversos estudios y resultan de enorme interés las reflexiones de Gudynas (2010) y la extensa compilación de Bebbington (2013) sobre el conjunto de la región andina. En la medida en que la inversión social de los regímenes progresistas depende de la expansión del extractivismo, advierten Moore y Velásquez (2013: 216-217), las iniciativas en esa dirección "en asociación con el capital multinacional pueden menoscabar los derechos de los pueblos indígenas y no indígenas históricamente marginados". Y todo ello, paradójicamente, en nombre de la izquierda, la soberanía nacional y el Sumak Kawsay. No menos inquietante es la estigmatización de la protesta anti-extractivista constatable en escenarios políticos tan aparentemente antagónicos como Ecuador y Bolivia por un lado y Perú por otro (Bebbington, 2013: 35-40).

14. Valga de muestra el hecho de que Oviedo es impulsor del Movimiento Sumak, "que es una organización holística que impulsa el Sumak Kawsay o Arte de Vivir, para que se reinstaure nuevamente en todos los rincones de la Madre Tierra, el ancestral y natural Sistema Armónico (Vitalismo) que ya fuera experimentado por más de 10.000 años por todos los pueblos solares y lunares del mundo entero. El vitalismo como una alter-nativa al capitalismo / socialismo" (Oviedo, 2012: 12). 
"Por eso decimos que el Buen Vivir posmoderno de los socialistas del siglo XXI es sólo una variación del Buen Vivir aristotélico, pero que no tiene casi nada del Sumak Kawsay andino. Y como este caso, la mayoría de lo que hemos leído hasta ahora sobre Sumak Kawsay o Suma Qamaña, como Buen Vivir-Vivir Bien, tiene muy poco o casi nada de los principios y postulados ancestrales andinos (cosmoconciencia), que es desde la única fuente que se puede entender a este sistema de vida y de conciencia, y no solamente político o económico. (...) El Buen Vivir en la Constitución Política del Ecuador y el Vivir Bien en la Constitución Política de Bolivia, es una mezcla o un 'champús' como la que gusta actualmente a la posmodernidad para hacer un 'mejunje' de todo un poco. Es una combinación del Buen Vivir platónico, con ciertos postulados cristianos y humanistas, algunos conceptos de los paradigmas ecologistas, étnicos, socialistas, y finalmente añadiendo ciertos principios generales del Sumak Kawsay, y a todo lo cual le llaman el Buen Vivir o Sumak Kawsay: de esta manera, consumando el irrespeto y desvalorización a la sabia y milenaria tradición andina" (Oviedo, 2012: 203-204).

En cualquier caso, la mirada de Escobar es sugerente y provocativa, pues induce a observar la realidad desde el prisma de unos puntos de vista que quieren vincular la praxis de los actores sociales subalternos con la concreción cotidiana de prácticas que van más allá de los imaginarios del Estado y del desarrollo. El debate vendrá, sin duda, por el lado de la necesaria contrastación empírica de esos supuestos: el hecho de que remarcados líderes, lideresas e intelectuales orgánicos de los movimientos sociales afirmen el mayor o menor radicalismo epistémico de sus luchas y propuestas, puede en realidad coincidir mucho, poco o nada con las profundas razones prácticas que mueven a las gentes de a pie a movilizarse a favor de la reforma agraria, en contra de la privatización del agua, por la estatalización de los hidrocarburos o, por qué no, en demanda de más fondos para proyectos de desarrollo. Habría que ver, en suma, qué hay tras las "comunidades de base" y las presuntas formas de economía "no-capitalista" que a decir de sus defensores se ubican tras las luchas subalternas: no vaya a ser que, una vez etnografiadas las prácticas cotidianas de los actores sociales, los discursos de esos intelectuales-activistas resulten demasiado alejados de la realidad y representen más un brindis al sol que una agenda política realmente asumida desde abajo.

\section{5. ¿VINOS VIEJOS EN ODRES NUEVOS?}

Los riesgos de una asunción acrítica, esencializada y descontextualizada de este tipo de propuestas han sido puestos de relieve por Viola (2011), quien señala de qué manera modas intelectuales ajenas a los pueblos indígenas y los países andinos - modas primermundistas, por más señas- pueden ejercer una fuerte influencia sobre las políticas de desarrollo en la región, habida cuenta la receptibilidad de las agencias de cooperación internacional (y de los gobiernos) a ese tipo de imágenes estereotipadas que se proyectan 
sobre determinados grupos (especialmente si son indígenas, como en Ecuador y Bolivia). En definitiva, parece que el Sumak Kawsay esté generando "una imagen que ha proporcionado a los llamados gobiernos posneoliberales un barniz de alternatividad discursiva que encubre unas prácticas económicas y un tratamiento real de la diversidad cultural que recuerdan mucho, por paradójico que parezca, a determinados aspectos de los regímenes nacionalistas y tecnocráticos de la década de los setenta" (Bretón, 2013: 73).

Para el caso del movimiento indígena ecuatoriano, los autores de este artículo tuvimos ocasión de constatar, mediante nuestras experiencias etnográficas en la sierra de ese país, la distancia oceánica que se fue generando entre los discursos etnificados de las élites y las condiciones de vida y las expectativas de las bases a lo largo de toda la década de los noventa; proceso que condujo a la CONAIE (Confederación de Nacionalidades Indígenas del Ecuador) a una aguda crisis de representatividad a partir de su paso por el gobierno nacional en 2003 (Báez y Bretón, 2006; Bretón, 2009) y la focalización de su actividad en la opción electoralista de Pachacutik (virtual brazo político del movimiento desde 1996). Vale la pena señalar en este sentido las curiosas reverberaciones que proyecta la imagen de las contradicciones entre los discursos esencializados y la praxis política de la actual Revolución Ciudadana, bien representada en esa acepción naïf del Sumak Kawsay, en relación a lo que fue la práctica del multiculturalismo neoliberal de la década de los noventa y los primeros años de este siglo XXI.

Como es bien sabido, la respuesta del establishment neoliberal (con Naciones Unidas y el Banco Mundial a la cabeza $)^{15}$ a la fortaleza de las plataformas étnicas en América Latina -bien manifestada, por ejemplo, en la emergencia de los neozapatistas chiapanecos (Dietz, 2004; Nash, 2006), el surgimiento de los discursos pan-mayas en Guatemala (Hale, 2002; Lembke, 2006), los levantamientos de la CONAIE en Ecuador (Zamosc, 1994 y 2004; Guerrero y Ospina, 2003) o las marchas de los cocaleros bolivianos (Viola. 2001; Albó, 2002; Botazzi y Rist, 2012)- fue la de la puesta en funcionamiento de todo un sofisticado entramado de políticas de reconocimiento. Willem Assies (2001) señaló, en esta línea, de qué manera el neoliberalismo iba más allá de las políticas económicas y de la reforma del Estado, incluyendo todo un proyecto cultural propio que se tradujo en la legalización de algunos derechos culturales de las minorías étnicas -los que no ponían en entredicho el patrón de acumulación- y en el rechazo sibilino 15. Sobre todo tras la proclamación del Decenio Internacional de las Poblaciones Indígenas (1995-2004) por la Asamblea General de Naciones Unidas en su resolución 48/163, de 21 de diciembre de 1993, dándole como meta principal "el fortalecimiento de la cooperación internacional para la solución de los problemas con que se enfrentan los pueblos indígenas en esferas tales como los derechos humanos, el medioambiente, el desarrollo, la educación y la salud". (http://www2.ohchr.org/spanish/issues/indigenous/decade.htm, lectura de 20 de enero de 2014). 
(pero tajante) del resto. De hecho, la inclinación del Banco Mundial de 1993 en adelante hacia las virtudes de las culturas indígenas ${ }^{16}$ tenía que ver con el talón de Aquiles que las demandas étnicas presentaban en su combate desigual contra el neoliberalismo periférico: su susceptibilidad de ser esencializadas, desvinculadas de los componentes puramente clasistas y, una vez segregadas de éstos, impulsadas y catapultadas -a través de la asunción de algunos aspectos de la ciudadanía étnica- como herramienta funcional y maleable en el desarrollo del propio neoliberalismo en un escenario en el que éste se considera de facto inevitable. De este modo, la proliferación de discursos y corrientes oficialistas de talante etnopopulista estaba en la base del ascenso -a menudo a través de la cooptación de líderes e intelectuales- de una praxis política sui generis para la que, como apuntara Héctor Díaz-Polanco (2005: 62), "el problema de la discriminación y exclusión desplaza el problema de la explotación y la desigualdad socioeconómica o la coloca en un plano muy secundario". De ahí el éxito del afianzamiento de un nuevo entramado interventor que, ideado en buena parte en el Banco Mundial, fomentó, parafraseando a Víctor Toledo (2005:73), el surgimiento de policy-makers indianistas, promoviendo metaretóricas pseudocientíficas sobre el desarrollo -del "capital social" al "empoderamiento", pasando por el "etnodesarrollo" o "desarrollo con identidad", el "enfoque de género" y la "gobernanza", por citar sólo algunos de los más trillados- que desvirtuaron y adulteraron el discurso de los derechos indígenas ${ }^{17}$.

Todo ello condujo a la consolidación de lo que algunos autores han calificado como regímenes de multiculturalismo neoliberal (Hale, 2002 y 2004; Díaz-Polanco, 2006; Martínez Novo, 2006; Bretón, 2008; o Boccara y Bolados, 2010); una estrategia política y económica que ha discurrido en una triple dirección: a) asumir y apoyar -incluso a través de modificaciones constitucionales- determinadas demandas de carácter cultural

16. Más de diez años después de la declaración del Decenio Internacional, el Banco Mundial seguía insistiendo en que trabajaba "para promover la participación y la inclusión de los pueblos indígenas de la región de América Latina y el Caribe en un proceso de desarrollo sostenible cuyos principales objetivos son: reducir la pobreza y promover el desarrollo sostenible; formar capacidades para el autodesarrollo entre los pueblos indígenas; fortalecer y mejorar los marcos institucionales y normativos; demostrar el importante papel que desempeñan los pueblos indígenas en el manejo de ecosistemas frágiles y en la conservación de la biodiversidad; difundir la experiencia adquirida. Estos objetivos se persiguen garantizando a la vez que el proceso de desarrollo fomente el respeto pleno a la dignidad, los derechos humanos y la cultura de los pueblos indígenas" (resaltado en el original) (http://nweb18.worldbank.org, lectura realizada el $1 \mathrm{de}$ junio de 2005).

17. "Términos como etnodesarrollo, inventados para referirse a modelos indígenas de desarrollo o a modelos alternativos que respetarían los valores y culturas locales, son paradójicos. Aunque indudablemente reflejan legítimas aspiraciones, se localizan en la línea, fina y contradictoria, de aceptar el desarrollo como una categoría universal" (Ribeiro, 2007:185). 
(derechos de los pueblos y nacionalidades al reconocimiento y visualización de su diferencia); b) dejar en un segundo plano (o simplemente obviar) aquellos planteamientos alternativos que pusieran en entredicho la lógica del modelo de acumulación dominante; y c) profundizar, en paralelo, la vía asistencialista (proyectista) de intervención sobre las comunidades. Esa vía proyectista presenta la virtud aparente de amortiguar el costo social del modelo neoliberal, al tiempo que, convenientemente manejada, ha permitido encauzar las expectativas de las dirigencias étnicas (y de sus bases) hacia el único espacio posible de negociación: el número y monto de los proyectos a implementar.

Ecuador fue un país pionero en el ensayo de ese tipo de patrones multiculturales. No es casual que fuera allí precisamente donde el Banco Mundial experimentó las virtudes del etnodesarrollo y el capital social a través del Proyecto de Desarrollo de los Pueblos Indígenas y Negros del Ecuador (PRODEPINE): entre 1998 y 2004, éste constituyó el pilar de las políticas públicas sobre esos $\operatorname{colectivos}^{18}$. PRODEPINE puede ser considerado como muestra paradigmática del tipo de intervención inducida desde el multiculturalismo neoliberal, tanto por sus resultados inocuos en tanto medida paliativa de la pobreza como por sus efectos sobre la cooptación de líderes y por su naturaleza inductora del proyectismo. Como sugerimos en un trabajo anterior,

"La gran novedad de PRODEPINE estribó en su orientación autogestionaria, limitándose a financiar y asesorar a las OSG para que controlasen y supervisasen las actuaciones sobre el territorio. Se perseguía que esas plataformas fueran capaces de priorizar las necesidades de sus comunidades filiales, de establecer perfiles de acción e incluso de contratar al personal técnico, siempre con el asesoramiento de la infraestructura burocrático-administrativa del Proyecto; infraestructura constituida con la finalidad de poner al alcance de esas OSG los recursos necesarios para materializar unos planes de desarrollo local (210 en total, habitualmente de ámbito parroquial) emanados a su vez de diagnósticos participativos preliminares (...). Esto significó en los Andes la activación de 379 sub-proyectos específicos ejecutados a través de 121 organizaciones indígenas. Más allá de las grandes cifras, sin embargo, el análisis pormenorizado de la forma en que se canalizaron las inversiones permite delinear cuatro líneas de interpretación del significado real de

18. La elección de Ecuador como laboratorio vino determinada en buena parte por la presencia en el país de uno de los movimientos indígenas más fuertes de la región, compuesto por diferentes pisos organizativos: organizaciones de base, de segundo grado (OSG), de tercer y cuarto grado (provinciales y regionales, respectivamente), hasta llegar a las grandes federaciones de la Costa, la Sierra y la Amazonía que componen la columna vertebral de la CONAIE. De hecho, a partir de la puesta en funcionamiento de PRODEPINE, ya se comenzaron a replicar -bien que a pequeña escala- iniciativas similares en Perú, Argentina, Guatemala y Bolivia. PRODEPINE, por lo tanto, nació con voluntad de reproducirse en otros escenarios caracterizados por la presencia de importantes contingentes de población indígena y/o de plataformas consolidadas de representación étnica. 
PRODEPINE: que tuvo mucho más de continuista que de innovador, visto desde la praxis del día a día; que sus gestores y evaluadores nunca se interpelaron sobre la calidad del capital social inducido; que su ejecución contribuyó a profundizar la división y la fragmentación del campesinado andino en base a criterios identitarios; y por último, que ha demostrado ser una eficaz correa de transmisión del proyectismo, con las limitaciones y las sombras que ello comporta en términos sociales y políticos" (Bretón, 2009: 100-101).

Con algunos matices en su modus operandi, pero fiel al mismo espíritu, fue también ejecutado en el altiplano ecuatoriano el Proyecto de Desarrollo Rural de Cotopaxi (PRODECO), operativo entre 2002 y 2007 y financiado por la Unión Europea. Dicho proyecto, hábilmente arropado por la retórica discursiva del desarrollo sostenible con identidad, pero estructurado desde un modelo jerárquico de control de las decisiones por parte de instancias tecnocráticas exógenas, supuso, más allá de los beneficios puntuales de la ejecución de obras en las comunidades indígenas seleccionadas, una clara operación política, compartida por la UE y el gobierno ecuatoriano, de debilitamiento de las bases sociales de apoyo al MICC (Movimiento Indígena y Campesino de Cotopaxi) y una clara interiorización por la población indígena del utilitarismo proyectista, vengan los proyectos de donde vengan y los traiga quien los traiga. En definitiva, una manifestación más de lo que Aníbal Quijano identifica como colonialidad de las subjetividades que consigue que los legítimos actores del proceso de transformación social naturalicen la injerencia de agentes externos en el diseño y el control de su cotidianeidad. Con anterioridad a nuestra etnografía post-facto de PRODECO, ya habíamos apuntado esa imbricación del desarrollo con la colonialidad.:

"Si el desarrollo puede interpretarse desde el marco teórico de la colonialidad, no es únicamente porque haya funcionado como nuevo mecanismo de penetración de los valores y principios de la modernidad eurocéntrica, normativizando un modelo de vida, sino porque, su discurso etnocéntrico, legitima, como ya lo hizo en el colonialismo de los siglos precedentes, las intervenciones de actores externos como elemento natural e incuestionable que, en muchos casos, no necesitan imponerse explícitamente, sino que son consentidas desde la internalización de los esquemas ideológicos que proponen una superioridad incuestionable de lo que viene de fuera" (Palenzuela, 2009: 136).

En ambas experiencias desarrollistas nos hallamos ante una acepción del etnodesarrollo que bastardea el contenido emancipador con el que fue planteado en la célebre Declaración de San José sobre etnodesarrollo y etnocidio en América Latina (1981). Especialmente en la expropiación del control político de las decisiones que debiera basarse en "el ejercicio de la capacidad social de un pueblo para construir su futuro aprovechando para ello las 
enseñanzas de su experiencia histórica y los recursos reales y potenciales, de acuerdo con un proyecto que se defina según sus propios valores y aspiraciones" (Bonfil, 1982: 131).

En este punto, vale la pena reflexionar sobre la manera en que ese multiculturalismo neoliberal fundamentó su praxis en una mirada, insistimos en ello, esencializada y estática de las culturas indígenas. Es como si, de pronto, las peculiaridades de lo andino (representado de manera unívoca y recurrente en la asunción de un comunitarismo inmanente a la misma condición andina) fueran aval suficiente, a los ojos de las agencias de desarrollo, de cara a garantizar la implementación de proyectos empoderativos de desarrollo con identidad (Andolina, Laurie y Radcliffe, 2009). En la medida, pues, en que esa manera folklorizante de entender la identidad étnica se convirtió en un formidable polo para atraer recursos de las agencias de desarrollo, devino así en un instrumento etnófago de cooptación en sintonía con los encuadramientos de las políticas neoliberales de reconocimiento. El acceso potencial a proyectos de diferente cuantía, orientación y naturaleza, fue el único campo de lucha en el que el modelo hegemónico terminó circunscribiendo, en los Andes equinocciales, a una población indígena cada vez más pauperizada, subproletarizada y con unas plataformas organizativas que fueron apartadas del control de la agenda del desarrollo y aceptaron su rol como simples veedores del proceso.

Ese fue el soporte sobre el que se construyó en Ecuador la arquitectura (Constitución de 2008) y la praxis del régimen de la Revolución Ciudadana, un tiempo nuevo (¿qué tan nuevo?) en el que, al parecer, se volteó la mirada hacia las llamadas culturas "ancestrales" en la búsqueda de un paradigma -el Sumak Kawsay- capaz de orientar el tránsito hacia una forma cualitativamente distinta de entender el desarrollo. En la construcción de esa imagen de ancestrabilidad contra-hegemónica, el papel de las miradas posestructuralistas fue, de manera directa e indirecta, muy importante. De manera directa en los momentos fundacionales del régimen, cuando en los debates que se articularon alrededor de la nueva Constitución se convirtieron en adalides del cambio de era que parecía llegar. De manera indirecta, dando cobertura intelectual y académica, aun distanciándose de los andariveles por donde transcurre hoy la acción política, a una mirada sobre el mundo indígena y afrodescendiente muy alejada de la etnografía y del espíritu substantivista que nunca debiera haber abandonado la Antropología crítica.

\section{CONCLUSIONES: ¿QUÉ HACER DESDE UNA ANTROPOLOGÍA CRÍTICA Y COMPROMETIDA?}

En primera instancia, recuperar el clásico axioma del análisis concreto de la realidad concreta, siempre desde una triple perspectiva: procesual, conflictual y contextual. Lo que significa, como sugiere el mismo Escobar, "volver a los lugares" y desplegar en ellos una estrategia investigadora sustentada en la articulación interdisciplinar de la Historia, 
la Economía Política y la Antropología Social para "sacar a la luz los marcos locales de producción de culturas y de identidades, de prácticas económicas y ecológicas que no cesan de emerger en comunidades de todo el mundo" (Escobar, 1997: 504) ${ }^{19}$.

Una antropología crítica del y sobre el desarrollo debe contribuir a la deconstrucción de los discursos hegemónicos que han impregnado las subjetividades de los actores desde la colonialidad del saber y del ser y que han conseguido naturalizar la universalidad de un conocimiento euro/etnocéntrico. Pero esa tarea no puede circunscribirse, como nos sugiere el posmodernismo diletante, al mero ejercicio de esgrima dialéctico entre posiciones teóricas contrastables en el campo académico. Porque "en primer lugar es necesaria la descolonización epistemológica para dar paso luego a una nueva comunicación intercultural, a un intercambio de experiencias y significaciones como la base de otra racionalidad" (Quijano, 1992: 447).

Estamos convencidos de que una etnografía densa, con un marco conceptual y un proceso epistemológico adecuados, podrá visualizar, en los proyectos de desarrollo, la asimetría en las relaciones de poder, los espacios de la confrontación -real/material y real/simbólica- de lógicas culturales y la emergencia de experiencias de emancipación surgidas en los intersticios del sistema. Se convertirá así, siempre que sea apropiada, cultural y políticamente, por los legítimos destinatarios del derecho a decidir, en un aporte decisivo para la descolonización del desarrollo. En esa misma línea, Gustavo Lins Ribeiro nos recomienda que

“...deben ser promovidas perspectivas mucho más abiertas, visiones sensibles a diferentes contextos culturales y políticos. Concomitantemente con la distribución de poder en el interior del campo del desarrollo, es necesario diseminar diferentes principios y sensibilidades así como reformar radicalmente las cosmologías e idiomas del desarrollo. Desarrollo no puede insistir en suponer que el Occidente es universal. Cooperación técnica no puede continuar usando una lengua contaminada con metáforas de desigualdad y jerarquía. Si las poblaciones e instituciones locales no se percibieran como sujetos activos del desarrollo, la apropiación de los proyectos por parte de las poblaciones locales continuará siendo un problema y la cooperación técnica continuará reforzando las desigualdades estructurales entre estadosnaciones" (Ribeiro, 2007: 190).

Si estamos convencidos dela necesidad urgente del proceso de decolonialidad, es necesario pasar de la resistencia a la alternativa y ello conlleva el compromiso del antropólogo con la producción de

“...nuestras propias formas de existencia social, liberadas de la dominación racista/etnicista/sexista, produciendo nuevas formas de comunidad, como nuestra

19. Por ello Escobar valora también las aportaciones de la Ecología Política. 
principal forma de autoridad política; produciendo libertad y autonomía para cada individuo, como expresión de la diversidad social y de la solidaridad; decidiendo democráticamente lo que necesitamos y queremos producir; acudiendo a y usando los máximos niveles de la tecnología para producir los bienes y valores que necesitamos; expandiendo la reciprocidad en la distribución del trabajo, de productos, de servicios; produciendo desde ese piso social la ética social alternativa a la del mercado y del lucro colonial/capitalista. Eso es lo que significa la producción democrática de una sociedad democrática" (Quijano, 2007:4).

En definitiva, apostamos por una antropología crítica y comprometida que pretenda, "no tanto el conocimiento por el conocimiento, sino el conocimiento para la acción o la intervención" (Sabelli, 1973: 77), que incorpore en sus modelos etnográficos las condiciones sociales de la producción de los datos y de su utilización en la toma de decisiones, "contribuyendo con ello al proceso de descolonización intelectual desde la interculturalidad bien entendida" (Palenzuela, 2009: 139). 


\section{REFERENCIAS BIBLIOGRÁFICAS}

Acosta, Alberto (2009) “El Buen Vivir, una oportunidad por construir". Ecuador Debate 75, pp. 33-48.

Acosta, Alberto (2011) "Riesgos y amenazas para el Buen Vivir". Ecuador Debate 84, pp.51-56.

Albó, Xavier (2002) "Bolivia: From Indian and Campesino Leaders to Councillors and Par-liamentary Deputies”. En SIEDER, Rachel (Ed.) Multiculturalism in Latin America. Indigenous Rights, Diversity and Democracy. London: Palgrave, pp. 74-102.

Andolina, Robert; Laurie, Nina; Radcliffe, Sarah (2009) Indigenous Development in the An-des.Culture, Power and Transnationalism. Durham: Duke University Press.

Assies, Willem (2000) "Indigenous peoples and reform of the State in Latin America". En Willem Assies, Gemma van der Haar, André J. Hoekema (eds.) The Challenge of Diver-sity. Indigenous Peoples and Reform of the State in Latin America. Amsterdam: ThelaThesis, pp. 3-21.

Báez, Sara; Víctor Bretón (2006) "El enigma del voto étnico o las tribulaciones del movimiento indígena: Reflexiones sobre los resultados de la primera vuelta electoral (2006) en las provincias de la Sierra". Ecuador Debate 69, pp. 19-36.

Beaucage, Pierre (2005) "Del desarrollo a la globalización: el antropólogo crítico y los actores sociales". en Gimeno, J.C y Palenzuela, P. (coords.) Culturas y desarrollo en la globalización capitalista. Sevilla: FAAEE/Fundación El Monte

Bebbington, Anthony (2013) Industrias extractivas, Conflicto social y dinámicas institucionales en la región andina. Lima: IEP/CEPES/Grupo Propuesta Ciudadana.

Boccara, Guillaume; Paola Bolados (2010) “QQué es el multiculturalismo? La nueva cuestión étnica en el Chile neoliberal”. Revista de Indias LXX(250), pp. 651-690.

Bonfil, Guillermo (1982) "El etnodesarrollo: sus premisas jurídicas, políticas y de organización". En Francisco Rojas (ed.) Etnodesarrollo y etnocidio en América Latina. San José de Costa Rica: CLACSO, pp. 131-145

Bottazzi, Patrick y Rist, Gilbert (2012) "Changing Land Rights Means, Changing Society: The Sociopolitical Effects of Agrarian Reforms under the Government of Evo Morales". Journal of Agrarian Change 12(4), pp. 528-551.

Bretón, Víctor (1997) Capitalismo, reforma agraria y organización comunal en los Andes. Una introducción al caso ecuatoriano. Lleida: Universitat de Lleida.

Bretón, Víctor (2001) Cooperación al desarrollo y demandas étnicas en los Andes ecuatorianos. Ensayos sobre indigenismo, desarrollo rural y neoindigenismo. Quito: FLACSO. 
Bretón, Víctor (2005) Capital social y etnodesarrollo en los Andes: la experiencia PRODEPINE. Quito: Centro Andino de Acción Popular.

Bretón, Víctor (2008) "From Agrarian Reform to Ethnodevelopment in the Highlands of Ecuador". Journal of Agrarian Change, 8, pp. 583-617.

Bretón, Víctor (2009) "La deriva identitaria del movimiento indígena en los Andes ecuatorianos o los límites de la etnografía”. En Martínez Novo, Carmen (Ed.) Repensando los movimientos indígenas. Quito: FLACSO, pp. 69-121.

Bretón, Víctor (2009b) “¿Continuarán muriendo de hambre millones de personas en el siglo XXI?”. Revista Española de Estudios Agrosociales y Pesqueros 224, pp. 69-109.

Bretón, Víctor (2012) Toacazo. En los Andes equinocciales tras la Reforma Agraria. Quito: FLACSO / Abya-Yala.

Bretón, Víctor (2013) "Etnicidad, desarrollo y "buen vivir": reflexiones críticas en perspectiva histórica". Revista Europea de Estudios Latinoamericanos y del Caribe, 95: 71-95.

Bretón, Víctor, Cortez, David y García, Fernando (2014) "En busca del Sumak Kawsay". Iconos, 48: 9-24.

Cardoso, Fernando H. (1972) "Dependency and Underdevelopment in Latin America". New Left Review 74, pp. 83-95.

Díaz-Polanco, Héctor (2005) "Los dilemas del pluralismo". En Dávalos, Pablo (Ed.) Pueblos indígenas, Estado y democracia. Buenos Aires: CLACSO, pp. 43-66.

Díaz-Polanco, Héctor (2006) Elogio de la diversidad. Globalización multiculturalismo y etnofagia. México: Siglo XXI.

Dietz, Gunter (2004) "From Indigenismo to Zapatismo: The Struggle for an Multiethnic Mexican Society". En Grey Postero, Nancy; Zamosc, Leon (eds.) The Struggle for Indigenous Rights in Latin America. Portland: Sussex Academic Press, pp. 32-80.

Escobar, Arturo (1998) La invención del Tercer Mundo. Construcción y deconstrucción deldesarrollo. Bogotá: Grupo Editorial Norma.

Escobar, Arturo (1999) “The Invention of Development”. Current History 98(631), pp. 382-387.

Escobar, Arturo (2000) "El lugar de la naturaleza y la naturaleza del lugar: globalización o posdesarrollo". En Viola, Andreu (ed.) Antropología del Desarrollo. Teorías y estudios etnográficos en América Latina. Barcelona: Paidós, pp. 169-216.

Escobar, Arturo (2005) "El 'postdesarrollo' como concepto y práctica social". En Mato, Daniel (Ed.) Políticas de economía, ambiente y sociedad en tiempos de globalización. Caracas: Universidad Central de Venezuela, pp. 17-31. 
Escobar, Arturo (2010) "América Latina en una encrucijada: ¿modernizaciones alternativas, posliberalismo o posdesarrollo?” En Víctor Bretón (Ed.) Saturno devora a sus hijos. Miradas críticas sobre el desarrollo y sus promesas. Barcelona: Icaria, pp. 33-85. Esteva, Gustavo (2000) “Desarrollo”. En Viola, Andreu (Ed.) Antropología del Desarrollo. Teorías y estudios etnográficos en América Latina. Barcelona: Paidós, pp. 67-101.

FAO (2013) El estado de la inseguridad alimentaria en el mundo 2013. Las múltiples dimensiones de la seguridad alimentaria. Roma: FAO.

Ferguson, James (1990) The Anti-politics Machine. Development, Depolitization and Breaucratic Power in Lesotho. Cambridge: Cambridge University Press.

Frank, André Gunder (2005 [1966]): “El desarrollo del subdesarrollo”. El nuevo rostro del capitalismo. Monthly Review Selecciones en castellano 4, pp. 144-157.

Furtado, Celso (1986 [1974]): El desarrollo económico: un mito. México: Siglo XX.

Gascón, Jordi (2010) “Del paradigma de la industrialización al de la Soberanía Alimentaria? Una comparación entre los gobiernos nacionalistas latinoamericanos del siglo XX y los pos-neoliberales a partir de sus políticas agrarias”. En Gascón, Jordi; Montagut, Xavier (eds.) Estado, movimientos sociales campesinos y soberanía alimentaria en América Latina. Barcelona: Icaria, pp. 215-259.

Guerrero, Fernando; Ospina, Pablo (2003) El poder de la comunidad. Ajuste estructural y movimiento indígena en los Andes ecuatorianos. Buenos Aires: CLACSO.

Gudynas, Eduardo (2009) "La ecología política del giro biocéntrico en la nueva Constitución de Ecuador”. Revista de Estudios Sociales 32, pp. 34-47.

Gudynas, Eduardo (2010) “Si eres tan progresista, ¿por qué destruyes la naturaleza?”. Ecuador Debate 79, pp. 61-82.

Hale, Charles (2002) "Does Multiculturalism Menace? Governance, Cultural Rights and the Politics of Identity in Guatemala”. Journal of Latin American Studies 34, pp. 485-524.

Hale, Charles (2004) "Rethinking Indigenous Politics in the Era of the Indio Permitido". NACLA Re-port on the Americas 38(2), pp. 16-22.

Lander, Edgardo (Ed.) (2005) La colonialidad del saber: eurocentrismo y ciencias sociales. Perspectivas Latinoamericanas. La Habana: Editorial de Ciencias Sociales.

Latouche, Serge (2008) La apuesta por el decrecimiento. ¿Cómo salir del imaginario dominante? Barcelona: Icaria.

Leef, Enrique (2006) "Complejidad, racionalidad ambiental y diálogo de saberes". Ponencia presentada en el I Congreso internacional interdisciplinar de participación, animación e intervención socioeducativa, celebrado en Barcelona en noviembre de 2005. 
Lembke Magnus (2006) In the Land of Oligarchs: Ethno-Politics and Struggle for Social Justice in the Indigenous-Peasant Movements of Guatemala and Ecuador. Doctoral Dissertation. Stockholm: Stockholm University.

Martínez Novo, Carmen (2006) Who Definies Indigenous?. Identities, Development, Intelectuals and the State in Northern Mexico. New Brunswick: Rutgers University Press.

Martínez Novo, Carmen (2013) “The Blacklash against Indigenous Rights in Ecuador's Citizen Revolution", Einsenstadt, Todd A. Danieldon, Michael S.; Bailon, Moisés Jaime; Sorroza, Carlos (eds.) Latin America's Multicultural Movements. New York: Oxford University Press, pp. 111-131.

Medina, Javier (2010) Mirar con los dos ojos. Insumos para profundizar el procoeso de cambio como un diálogo de matrices cvilizatorias. La Paz: La Mirada Salvaje.

Mignolo, Walter (2000) "La colonialidad a lo largo y a lo ancho: el hemisferio occidental en el horizonte colonial de la modernidad". Lander, Edgardo (Ed.) La colonialidad del saber: eurocentrismo y ciencias sociales. Perspectivas Latinoamericanas. Buenos Aires: CLACSO, pp. 55-85.

Mignolo, Walter (2003) Historias locales / Diseños globales: colonialidad, conocimentos subalternos y pensamiento fronterizo. Madrid: Akal.

Mignolo, Walter (2010) Desobediencia epistémica: retórica de la modernidad, lógica de la colonialidad y gramática de la descolonialidad. Buenos Aires: Ediciones del Signo.

Nash, June C. (2006) Visiones mayas. El problema de la autonomía en la era de la globalización. Buenos Aires: Editorial Antropofagia.

Oviedo, Atawallpa (2012) ¿Qué es el sumak kawsay?. La Paz: Sumak Editores.

Palenzuela, Pablo (2009) "Mitificación del desarrollo y mixtificación de la cultura: el etnodesarrollo como alternativa”. Iconos, pp. 127-140.

Palenzuela, Pablo (2011) "Discursos y prácticas del desarrollismo en los Andes ecuatorianos: el proyecto PRODECO en Cotopaxi”. En Palenzuela, Pablo y Olivi, Alessandra (eds.) Desarrollo y etnicidad en los Andes. Sevilla: Universidad de Sevilla, pp. 53-82.

Quijano, Aníbal (1992) “Colonialidad y modernización/racionalidad”. Héctor Bonilla (comp.) Los conquistados de 1492 y la población indígena de las Américas. Quito: LibriMundi/Tercer Mundo

Quijano, Aníbal (2000) “El fantasma del desarrollo en América Latina”. Revista Venezolana de Economía y Ciencias Sociales, 2: 73-91 
Quijano, Aníbal (2000b) "Colonialidad del poder, eurocentrismo y América Latina", Lander, Edgardo (Ed.) La colonialidad del saber: eurocentrismo y ciencias sociales. Perspectivas Latinoamericanas. Buenos Aires: CLACSO, pp. 201-246.

Quijano, Aníbal (2007) "Des/colonialidad del poder: el horizonte alternativo". Observatorio Latinoamericano de Geopolítica. Lima.

Ribeiro, Gustavo Lins (2007) "Poder, redes e ideología en el campo del desarrollo". En Tabula rasa. Bogotá, 6: 173-193.

Rist, Gilbert (2002) El desarrollo: historia de una creencia occidental. Madrid: Instituto Universitario de Desarrollo y Cooperación/UCM/ Los Libros de la Catarata.

Rostow, Walt W. (1961) Las etapas del crecimiento económico: un manifiesto no comunista. México : Fondo de Cultura Económica.

Sabelli, François (1993) Recherche anthropologique et développement. París: Maison des Sciences del'Homme.

Sánchez-Parga, José, (2011) "Discursos retrorevolucionarios: sumak kawsay, derechos de la naturaleza y otros pachamamismos". Ecuador Debate 84, pp. 51-56.

Sogge, David (1998) Compasión y cálculo. Un análisis crítico de la cooperación no gubernamental al desarrollo. Barcelona: Icaria.

Sogge, David (2004) Dar y tomar. ¿Qué sucede con la ayuda internacional? Barcelona: Icaria.

Stefannoni, Pablo (2010) “A dónde nos lleva el pachamamismo?". Debate ordenado sobre el Pachamamismo. http://es.scribd.com/doc/33675955/Debate-Ordenado-Sobre-ElPachamamismo.

Toledo, Víctor (2005) "Políticas indígenas y derechos territoriales en América Latina: 1990-2004. ¿Las fronteras de la globalización?”. En Dávalos, Pablo (Ed.) Pueblos indígenas, Estado y democracia. Buenos Aires: CLACSO, pp. 67-102.

Tortosa, José María (2009) “El futuro del maldesarrollo”. Revista Obets 4, pp. 67-83.

Tortosa, José María (2009b) "Sumak Kawsay, Suma Qamaña, Buen Vivir". Madrid: Fundación Carolina. http://www.fundacioncarolina.es/es-ES/nombrespropios / Documents

Viola, Andreu (2001) ;Viva la coca, mueran los gringos! Movilizaciones campesinas y etnicidad en el Chapare (Bolivia). Barcelona: Universidad de Barcelona.

Viola, Andreu (2010) "Desarrollo, bienestar e identidad cultural: del desarrollismo etnocida al Sumaq Kawsayen los Andes". En Palenzuela, Pablo y Olivi, Alessandra (eds.) Desarrollo y etnicidad en los Andes. Sevilla: Universidad de Sevilla, pp. 255-302. 
Viola, Andreu (2013) "Discursos pachamamistas versus políticas desarrollistas: el debate sobre el sumak kawsay en los Andes". Iconos, 48:55-72

Walsh, Catherine (2009) Interculturalidad, Estado, sociedad: luchas (de)coloniales de nuestra época, Quito: UASB/Abya-Yala.

Wallerstein, Inmanuel, (2004) "El ascenso y futura decadencia del sistema-mundo capitalista: conceptos para un análisis comparativo". En WALLERSTEIN, Immanuel: Capitalismo histórico y movimientos antisistémicos. Madrid: Akal, pp. 85-114. 